\title{
Rebuild doctor-patient trust in medical service delivery in China
}

\author{
Liang Du, Jia Xu, Xu Chen, Xuexue Zhu, Yu Zhang, Ruiheng Wu, Haoqiang Ji \& Ling Zhou ${ }^{\bowtie}$
}

Doctor-patient trust is not strong in China, but studies examining this factor remain insufficient. The present study aimed to explore the effect of doctor-patient communication, medical service quality, and service satisfaction on patient trust in doctors. Five hundred sixty-four patients with tuberculosis participated in this cross-sectional study in Dalian, China. They completed questionnaires assessing socio-demographic characteristics, doctor-patient communication, medical service quality, service satisfaction and patient trust in medical staff. A structural equation model was applied to examine the hypotheses, and all the study hypotheses were supported: (1) doctor-patient communication, medical service quality and service satisfaction were positively associated with building doctor-patient trust; (2) service quality positively mediated the relationship between doctor-patient communication and trust; (3) medical service satisfaction positively mediated the relationship between doctor-patient communication and trust; (4) medical service satisfaction positively mediated the relationship between medical service quality and doctor-patient trust; and (5) medical service quality and service satisfaction were the positively sequential mediators between communication and doctor-patient trust. Based on these findings, improvements in doctor-patient communication, medical service quality, and service satisfaction are the important issues contributing to the rebuilding of doctorpatient trust in medical service delivery.

A good doctor-patient relationship is the fundamental factor ensuring a normal medical process. Doctor-patient trust is the global attribute of treatment relationships, and it usually encompasses subsidiary features, such as communication, medical service quality and satisfaction ${ }^{1}$. Over time, a gradual deterioration of doctor-patient trust appears to be an inevitable trend for the healthcare system worldwide. A survey study conducted in the USA indicated that $82.2 \%$ of patients with chronic diseases trust their doctors ${ }^{2}$. Another study in European regions suggested that the Italian-speaking patients exhibited high trust in doctors, but less than half of the French-speaking patients had trust in doctors ${ }^{3}$. A literature review reported an insufficient level of doctor-patient trust in East Asia, including Mainland China, Hong Kong, Taiwan, South Korea and Japan; patients in China reported suboptimal trust in doctors because of less doctor-patient communication and few shared decisionmaking processes ${ }^{4}$.

In the past decade, the relationship between the doctor and patient has become increasingly worse in China ${ }^{5,6}$. Frequent incidents of patients performing offending and adverse events against health care workers in the form of verbal and physical abuse, injury, and even urder $^{7-9}$, which is not beneficial to the development of medical service in China ${ }^{10,11}$. The root cause of doctor-patient conflicts is the issue of trust between doctors and patients, particularly patients' trust towards medical staff ${ }^{11}$. If patients express less trust in doctors, on the one hand, patients will doubt the doctors' treatment regimen and will not participate in treatment with positivity regarding the outcome, which may lead to non-ideal treatment effects and arouse patients' negative feelings about the doctors' professional authority and their consideration of doctors as retailers selling medical services ${ }^{12}$. On the other hand, subsequently, doctors observe a substantial decrease in patients' treatment expectations, which increases the dissatisfaction of doctors with patients, thus leading to the occurrence of adverse events between doctors and patients ${ }^{13,14}$. Patient trust in medical staff has been defined as the belief of patients that doctors have the skills necessary for diagnosis and treatment and that they will first consider the patients' interests, thereby allowing patients to accept the medical services and be reassured ${ }^{15}$. Doctor-patient trust plays an important role in the medical process, and insufficient trust might be associated with an adverse medical service experience ${ }^{16}$, lower treatment adherence of patients ${ }^{17}$, and even treatment failure ${ }^{18}$. Therefore, studies aiming to explore the mechanism underlying the effect of doctor-patient trust are necessary and urgently needed.

Although doctor-patient trust is not optimistic in China, few studies have been conducted on doctor-patient trust. Various intricate factors may be associated with doctor-patient trust, including socioeconomic characteristics, medical personnel, medical service institutions, and social networking services ${ }^{6,19-21}$. However, knowledge 
of whether the medical service delivery process is related to doctor-patient trust is limited. A recent quantitative study using dyadic analysis found that a higher quality of communication positively predicted doctor-patient trust $^{22}$. Additionally, the medical service quality, which was mainly measured based on the patient's perception and feelings, was identified as another important factor associated with doctor-patient trust ${ }^{23}$. Besides, doctor-patient trust significantly predicted patients' satisfaction with medical services in a previous study ${ }^{24}$, but few studies have yet explored the effect of service satisfaction on doctor-patient trust.

When receiving medical services, patients are unable to perceive the quality of and satisfaction with medical services if communication between doctors and patients is lacking. Ensuring the quality of medical services is an important part of operating a hospital, which is also beneficial to improving the health of a sub-healthy population ${ }^{25}$. The assessment of the medical service quality may be difficult and complex in practice, but doctors' attitudes, medical behaviours, and professional skills are shared among studies ${ }^{26,27}$. Medical service quality is described as conforming to three dimensions, outcome, environmental quality, and interaction, among which the interaction quality exhibited the greatest effect on overall service quality. They also concluded that service-related attitudes, behaviours, and expertise are components of interaction quality, namely, functional quality. Based on cognitive psychology theory. The concept of customer-perceived service quality depends on the comparison between service expectation and perceived actual service performance, in which only when perceived actual service performance was greater than service expectation would customers perceive a high level of service quality. With the peculiarity of medical services, doctor-patient communication is associated with what medical services the doctors would provide, which may eventually influence the medical service quality that patients receive ${ }^{28,29}$.

Patient-perceived service satisfaction might be considered as a prospective outcome of healthcare, which incorporates interpersonal relationships, specific components of medical technology, and the outcomes of care ${ }^{26}$. Measurements of satisfaction with medical services are a complicated issue. Although the measurement of patient satisfaction has been studied for years, a consensus on its definition and the best methodology to measure it has not been achieved. Dissatisfactory medical service is a symptom of one flawed system that victimizes both patients and doctors, and directly leads to violence in the medical process ${ }^{7,11}$. According to stimulus response theory, when an individual receives a stimulus from the outside world, he/she may form new behaviours or attitudes in the future if the contents of the stimulus are accepted ${ }^{30}$. Previous studies have confirmed that highquality doctor-patient communication contributes to patients' satisfaction, which then may tend to establish the patients' trust in medical staff ${ }^{11,31,32}$.

Social exchange theory (SET) is a value expectancy theory that involves an assessment between individual expectations of the outcomes of an action, as well as their subjective values for those outcomes ${ }^{33}$. If the benefits of the outcome are more rewarding than the cost of the activity, this relationship will be valued and the individual will be more likely to engage in the collaborative behaviour again in the future. In medical service delivery, patients require better treatment and quality of service, which requires that patients trust in doctors; doctors tend to pursue patients' satisfaction and trust, both of which require effective communication with each other. SET suggests that both doctors and patients are motivated to improve communication in medical service delivery if they expect a positive outcome, indicating that doctors would provide the best service possible to meet the patients' needs ${ }^{34}$. With high medical service quality supplied by doctors, the patients may have a greater sense of satisfaction and trust towards their doctors.

China is now the country with the second highest tuberculosis (TB) burden in the world, and TB is also the crucial infectious disease threatening the health of Chinese people ${ }^{35,36}$. In the anti-TB treatment process, the problem of distrust between doctors and patients occurs frequently, mainly because of the factors listed below. (1) Although China has been implementing a policy of free treatment for TB, patients still face a serious financial burden $^{37}$. (2) The privacy of TB patients is a prominent concern, and patients may fear that doctors reveal their tuberculosis status to others, which will lead to social discrimination, alienation, and stigma from public ${ }^{38,39}$. (3) During the continuation phase of anti-TB treatment, some patients experience unresolved TB symptoms or adverse drug reactions, although they are being treated with their regular medication ${ }^{40}$. Suboptimal patient trust in doctors gives rise to doctor-patient conflict and prejudice, and patients' poor treatment adherence, which may further lead to the aggravation of their illness, treatment interruption or failure, relapse, infection of others, and obstruction of the progress of TB treatment and control in China. Based on these findings and using patients with TB as study sample, the purpose of present study was to test the hypotheses (see Fig. 1) that (1) doctor-patient communication, medical service quality and service satisfaction directly benefited building doctor-patient trust (H1); (2) service quality mediated the relationship between doctor-patient communication and doctor-patient trust (H2); (3) medical service satisfaction mediated the relationship between doctor-patient communication and doctor-patient trust (H3); (4) medical service satisfaction mediated the relationship between medical service quality and doctor-patient trust (H4); and (5) medical service quality and service satisfaction were the sequential mediators from doctor-patient communication to doctor-patient trust (H5). According to these research hypotheses, we attempted to describe methods to rebuild doctor-patient trust in medical service delivery.

\section{Methods}

Study design and setting. This multi-centre survey was conducted between June 20, 2019, and August 31,2019 , and four medical institutions in Dalian, Liaoning Province, in northeast China were involved ${ }^{41}$. The four TB medical institutions, which served different types of patients, were chosen according to their institution level and location. The first was a tertiary hospital that mainly serves patients across the whole city, particularly critically ill and urban patients. The second was a county hospital that serves both rural and urban patients with TB. The other two medical institutions were tuberculosis dispensaries, which only serve local patients with a milder disease. 


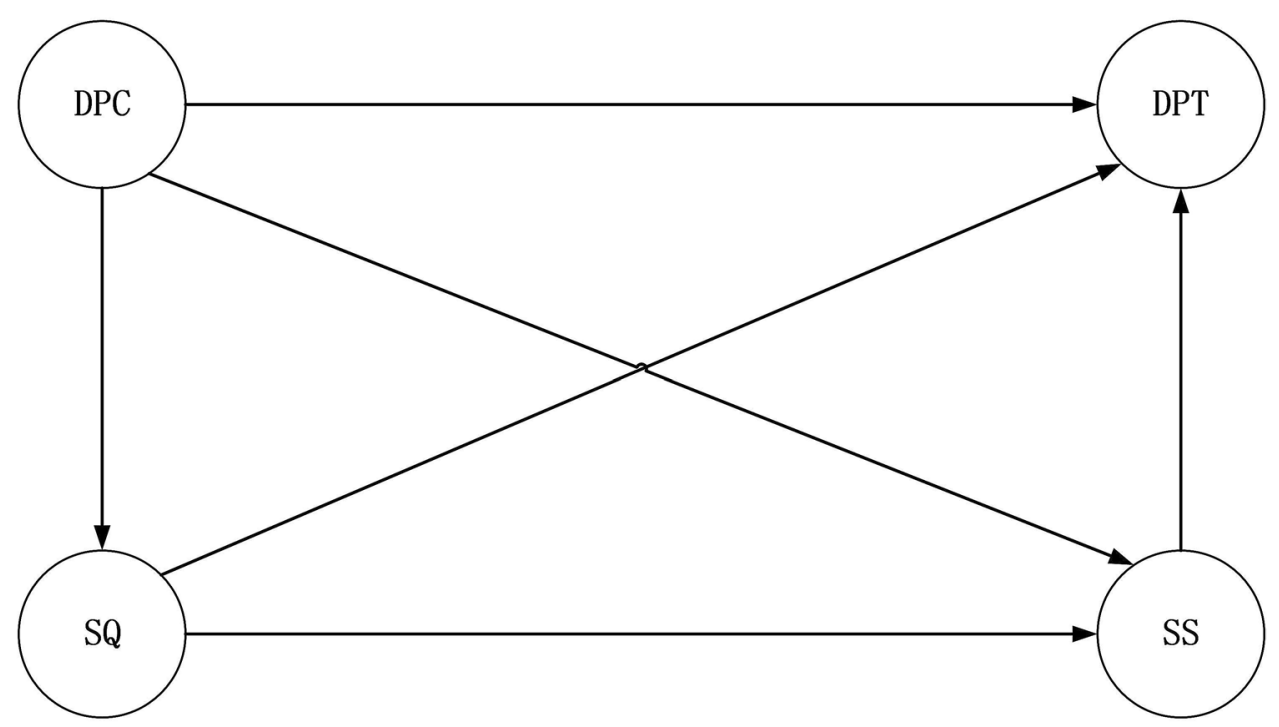

Figure 1. The research model based on the hypotheses. DPC doctor-patient communication, SQ service quality, $S S$ service satisfaction, $D P T$ doctor-patient trust.

Participants. Outpatients with pulmonary TB who had been receiving treatment for $>2$ months were eligible participants. We excluded patients aged $<15$ years and patients who were unable to complete the questionnaire due to a mental or psychological illness. All participants were told that their privacy would be protected and they were free to withdraw from the study at any time. The participants signed an informed consent form prior to participation in our study. A parent or legal guardian provided informed consent for any patient under the age of 18. Detail description can be found in our another study ${ }^{41}$.

Ethics procedure. The study protocol was reviewed and approved by the ethics committee of Dalian Medical University, Liaoning province, China. All methods in our study were carried out in accordance with relevant guidelines and regulations (Declaration of Helsinki).

Measurement. Socio-demographic characteristics of the participants were collected, including gender, age, marriage, immigration status, residence, education, monthly income and hospital type. Additionally, doctorpatient communication, medical service quality, service satisfaction and doctor-patient trust were measured in this study.

Doctor-patient communication. The communication between doctor and patients was measured with a 4-item scale, which was a component of the Consumer Assessment of Healthcare Providers and Systems (CAHPS) that involved doctor-patient communication, access to needed medical service, timely healthcare, and other factors ${ }^{42}$. Response options for each item ranged from $1=$ never to $5=$ always. Higher scores indicate low-level communication. The reliability coefficient of Cronbach's $\alpha=0.89$ was for the original CAHPS scale ${ }^{43}$ and $\alpha=0.85$ in this study.

Medical service quality. Based on a literature review and expert consultation, we compiled three items to measure service quality. We asked the patients about their experience from three aspects: (1) the medical workers did their best to meet your healthcare and nursing needs; (2) the skills and expertise of the medical workers were very good; (3) the attitudes and behaviours of the medical workers were very careful. Participants responded to the 3 items on a 5 -point Likert-type scale $(1=$ strongly disagree to $5=$ strongly agree $)$. The reliability coefficient of Cronbach's $\alpha$ for the 3 -item scale was 0.65 .

Service satisfaction. Participants in this study are outpatients with TB who have frequent hospital visits, and thus we considered that the main components of perceived service satisfaction were doctors' explanations of patient health conditions, precautions related to the application of anti-TB drugs, and lifestyle and health guidance, such as diet and physical exercise. Based on a literature review and expert consultation, we compiled three items to measure service satisfaction: (1) how satisfied are you with the doctor's explanation of your disease; (2) how satisfied are you with the doctor's explanation of the drug used and its side effects; and (3) how satisfied are you with the doctor's instructions regarding your life and health. Participants responded to the 3 items on a 5 -point Likert-type scale ( $1=$ strongly dissatisfied to $5=$ strongly satisfied). The reliability coefficient of Cronbach's a for the 3 -item scale was 0.82 . 
Doctor-patient trust. The self-reported trust of the patient in the doctor was measured using the sub-scale of the Trust in Physician scale, which consisted of four items: (1) you completely trust your doctor's decisions about which treatments are best for you; (2) your doctor only thinks about what is best for you; (3) you have no worries about putting your life in your doctor's hands; and (4) overall, you have complete trust in your doctor ${ }^{44,45}$. Trust was divided into various dimensions, and this 4-item subscale measured the patients' global trust in doctors. Participants responded to the four items on a 5 -point Likert-type scale $(1=$ strongly disagree to $5=$ strongly agree). The reliability coefficient of Cronbach's $\alpha=0.93$ for the Trust in Physician scale ${ }^{45}$, and $\alpha=0.85$ for the 4 -item subscale in this study.

Statistical analysis. A sample of 593 records containing the questionnaire data was collected, and we used EpiData software version 3.1 (The EpiData Association, Odense, Denmark) to establish a database to enter the questionnaire data. We deleted records containing $>20 \%$ missing values, which led to the inclusion of 564 eligible records in the final sample. We mainly used frequencies and percentages to describe the study sample.

When considering more than one potential mediating variable and complex relationships in the research model, we used the structural equation model (SEM) to test the hypotheses. SEM finds the potential and important associations to produce a more complete picture of the causal effect mechanism, and it specifically incorporates the measurement error in the research model ${ }^{46}$. Additionally, the confirmatory factor analysis (CFA) was performed to examine the validity and reliability of constructs and was combined with SEM to improve the research model ${ }^{46}$. Factor loading (F.L.), composite reliability (CR), average of variance extracted (AVE) and discriminant validity were reported. Additionally, the comparative fit index (CFI), Tucker-Lewis index (TLI), root mean squared error of approximation (RMSEA), and standardized root mean square residual (SRMR) were calculated to test the fit of the model. The mediation models were constructed using bootstrapping, a nonparametric test that does not rely on assumptions of a normal distribution. Using this method, a significant indirect effect indicated by a $95 \%$ confidence interval (CI) not including zero provides evidence for the presence of mediation.

The SPSS 25.0 statistical package (IBM Corporation, Armonk, State of New York) was used to preliminarily analyse data obtained from the survey. According to the principle of the structural equation model, our conceptual model was then tested using Mplus 7.0 statistical analysis software (Muthén \& Muthén, Los Angeles, CA, USA), and the multivariable linear regression model was used in our study. Two-sided $P<0.05$ was considered to indicate statistical significance.

\section{Results}

Sample description. Among the 564 participants, approximately twice as many male patients (66.31\%) as female patients $(33.69 \%)$ were included. The mean age was 47.41 years and the median was 49 years (interquartile range 31 years). Most of the participants were married (71.10\%). Only 93 (16.49\%) were migrants, and slightly more rural patients $(52.66 \%)$ than urban patients $(47.34 \%)$ were analysed. Middle school education $(34.22 \%)$ was the most common education level, and the percentages among the other education levels were similar. The number of the participants decreased with the increase in monthly income and only 61 participants $(10.82 \%)$ reported a monthly income of more than 5000 yuan. The linear regression analysis showed that only hospital type was significantly associated with doctor-patient trust, and the county hospital exerted the greatest effects on this outcome (Table 1).

Reliability and validity of the constructs. According to the factor analysis, all factor loading values for the items were $>0.5$, implying that these items measured the constructs well. The lowest value of the CR was 0.669 , indicating that the constructs exhibited acceptable composite reliability. Additionally, the values of $\sqrt{\text { AVE }}$ sere greater than the values of the Pearson correlation coefficients between constructs in the same row or column, which exhibited ideal discriminant validity. In summary, these constructs exhibited good reliability and validity ${ }^{47}$ (Table 2).

Test of the fitting index of the research model. Using the maximum likelihood method, the research model exhibited an ideal goodness of fit and the fitness indexes all satisfied the practical criteria or threshold values (Chi-square test of the model fit $=210.535$; degrees of freedom $=71$; Chi-square $/ \mathrm{DF}<3$; $\mathrm{CFI}=0.962>0.95$; $\mathrm{TLI}=0.952>0.95$; RMSEA $=0.059<0.08$; $\mathrm{SRMR}=0.039<0.08)$, indicating that the data fitted our conceptual research model very well ${ }^{48}$ (Table 3 ).

Results of the linear regression model. Doctor-patient communication positively predicted the service quality $(b=0.465, P<0.001)$, and the $R$-square value was 0.216 . Additionally, satisfaction with the medical service was also significantly and positively interpreted by doctor-patient communication $(b=0.554, P<0.001)$ and service quality $(b=0.228, P=0.001)$, and the $R$-square value was 0.476 . Finally, doctor-patient trust was positively interpreted by doctor-patient communication $(b=0.205, P=0.016)$, service quality $(b=0.409, P<0.001)$ and service satisfaction $(b=0.231, P=0.014)$, and the $R$-square value was 0.495 . Obviously, the first hypotheses were supported by these results (Table 4 and Fig. 2).

Total and indirect effects on doctor-patient trust. Using the bootstrapping method, $95 \%$ bias-corrected confidence intervals (CIs) without "zero" indicate significant mediating and total effects ${ }^{49}$. The total effect of service quality on doctor-patient trust was $0.462(95 \% \mathrm{CI}(0.303,0.656))$. Medical service quality significantly predicted doctor-patient trust via patient-perceived satisfaction $(P=0.050,95 \% \mathrm{CI}(0.014,0.125))$, and the ratio of the indirect effect to total effect was $11.5 \%$. The total indirect effect of doctor-patient communication on doc- 


\begin{tabular}{|c|c|c|c|c|}
\hline Variable & Description & $\mathrm{N}(\%)$ & Est. (b) & P-value \\
\hline \multirow{2}{*}{ Gender } & Male & $374(66.31 \%)$ & Reference & \\
\hline & Female & $190(33.69 \%)$ & 0.146 & 0.530 \\
\hline \multirow{4}{*}{ Age (years) } & $<21$ & $26(4.61 \%)$ & Reference & \\
\hline & $21-40$ & $196(34.75 \%)$ & 0.112 & 0.835 \\
\hline & $41-60$ & $181(32.09 \%)$ & 0.021 & 0.971 \\
\hline & $>60$ & $161(28.55 \%)$ & 0.061 & 0.920 \\
\hline \multirow{2}{*}{ Marriage } & Married & $401(71.10 \%)$ & Reference & \\
\hline & Unmarried/widowed & $163(28.90 \%)$ & 0.007 & 0.980 \\
\hline \multirow{2}{*}{ Immigration } & Yes & $93(16.49 \%)$ & Reference & \\
\hline & No & $471(83.51 \%)$ & -0.029 & 0.919 \\
\hline \multirow{2}{*}{ Residence } & Urban & $267(47.34 \%)$ & Reference & \\
\hline & Rural & $297(52.66 \%)$ & -0.088 & 0.755 \\
\hline \multirow{4}{*}{ Education } & Primary or below & $123(21.28 \%)$ & Reference & \\
\hline & Middle school & $193(34.22 \%)$ & 0.208 & 0.488 \\
\hline & High school & $120(21.28 \%)$ & 0.293 & 0.436 \\
\hline & College or above & $128(22.70 \%)$ & 0.239 & 0.564 \\
\hline \multirow{4}{*}{ Income (yuan/month) } & $<1000$ & $223(39.54 \%)$ & Reference & \\
\hline & $1000-3000$ & $129(22.87 \%)$ & 0.347 & 0.213 \\
\hline & $3000-5000$ & $151(26.77 \%)$ & 0.366 & 0.207 \\
\hline & $>5000$ & $61(10.82 \%)$ & 0.089 & 0.823 \\
\hline \multirow{3}{*}{ Hospital type } & Tertiary hospital & $199(35.38 \%)$ & Reference & \\
\hline & County hospital & $152(26.95 \%)$ & 1.605 & $<0.001$ \\
\hline & TB dispensaries & $213(37.77 \%)$ & 0.607 & 0.037 \\
\hline
\end{tabular}

Table 1. Socio-demographic characteristics and the associations with doctor-patient trust.

\begin{tabular}{|c|c|c|c|c|c|c|c|c|}
\hline \multirow[b]{2}{*}{ Construct } & \multirow[b]{2}{*}{ Items } & \multirow[b]{2}{*}{ F.L. range } & \multirow[b]{2}{*}{ CR } & \multirow[b]{2}{*}{ AVE } & \multicolumn{4}{|c|}{ Discriminant validity } \\
\hline & & & & & DPC & SQ & SS & DPT \\
\hline DPC & 4 & $0.794-0.811$ & 0.879 & 0.645 & 0.803 & & & \\
\hline SQ & 3 & $0.546-0.734$ & 0.669 & 0.406 & 0.465 & 0.637 & & \\
\hline SS & 3 & $0.670-0.869$ & 0.828 & 0.620 & 0.659 & 0.485 & 0.787 & \\
\hline DPT & 4 & \begin{tabular}{|l}
$0.682-0.828$ \\
\end{tabular} & 0.853 & 0.593 & \begin{tabular}{|l|l|}
0.548 \\
\end{tabular} & \begin{tabular}{|l|l|}
0.616 \\
\end{tabular} & \begin{tabular}{|l|l|}
0.565 \\
\end{tabular} & \begin{tabular}{|l|l|}
0.770 \\
\end{tabular} \\
\hline
\end{tabular}

Table 2. Results of the reliability and validity tests. The bold values shown on the diagonal are $\sqrt{\mathrm{AVE}} \mathrm{s}$, and the values under the bold value represent the Pearson correlation coefficients between constructs. DPC doctor-patient communication, $S Q$ service quality, SS service satisfaction, DPT doctor-patient trust, F.L. factor loading, $C R$ composite reliability, $A V E$ average of variance extracted.

\begin{tabular}{|l|l|l|l|}
\hline Index & Criteria & Research model & Support or not \\
\hline Chi-square & Smaller is better & 210.535 & Support \\
\hline DF & Larger is better & 71 & Support \\
\hline Chi-square/DF & $3>$ Chi-square/DF $>1$ & 2.96 & Support \\
\hline CFI & $>0.90$ & 0.962 & Support \\
\hline TLI & $>0.90$ & 0.952 & Support \\
\hline RMSEA & $<0.08$ & 0.059 & Support \\
\hline SRMR & $<0.08$ & 0.039 & Support \\
\hline
\end{tabular}

Table 3. Fitting index of the research model. DF degrees of freedom, CFI comparative fit index, TLI TuckerLewis index, RMSEA root mean squared error of approximation, $S R M R$ standardized root mean square residual. 


\begin{tabular}{|c|c|c|c|c|c|c|c|c|}
\hline \multirow[b]{2}{*}{ DV } & \multirow[b]{2}{*}{ IV } & \multirow[b]{2}{*}{ Est. (b) } & \multirow[b]{2}{*}{ S.E. } & \multirow[b]{2}{*}{ Est./S.E. } & \multirow[b]{2}{*}{$P$-value } & \multicolumn{2}{|c|}{$\begin{array}{l}\text { Bootstrap } 1000 \text { times 95\% } \\
\text { CI (bias-corrected) }\end{array}$} & \multirow[b]{2}{*}{$R$-square } \\
\hline & & & & & & Lower & Upper & \\
\hline SQ & DPC & \begin{tabular}{|l|}
0.465 \\
\end{tabular} & \begin{tabular}{|l|}
0.067 \\
\end{tabular} & 6.933 & $<0.001$ & 0.330 & 0.586 & 0.216 \\
\hline \multirow{2}{*}{ SS } & DPC & 0.554 & 0.061 & 9.084 & $<0.001$ & 0.424 & 0.646 & 0.476 \\
\hline & SQ & 0.228 & 0.068 & 3.344 & 0.001 & 0.094 & 0.363 & \\
\hline \multirow{3}{*}{ DPT } & DPC & 0.205 & 0.085 & 2.419 & 0.016 & 0.050 & 0.379 & 0.495 \\
\hline & SQ & 0.409 & 0.095 & 4.328 & $<0.001$ & 0.248 & 0.618 & \\
\hline & SS & 0.231 & 0.094 & 2.455 & 0.014 & 0.078 & 0.464 & \\
\hline
\end{tabular}

Table 4. Research model regression weight and hypothesis. DPC doctor-patient communication, $S Q$ service quality, $S S$ service satisfaction, $D P T$ doctor-patient trust, S.E. standard error, $D V$ dependent variable, $I V$ independent variable, $C I$ confidence interval.

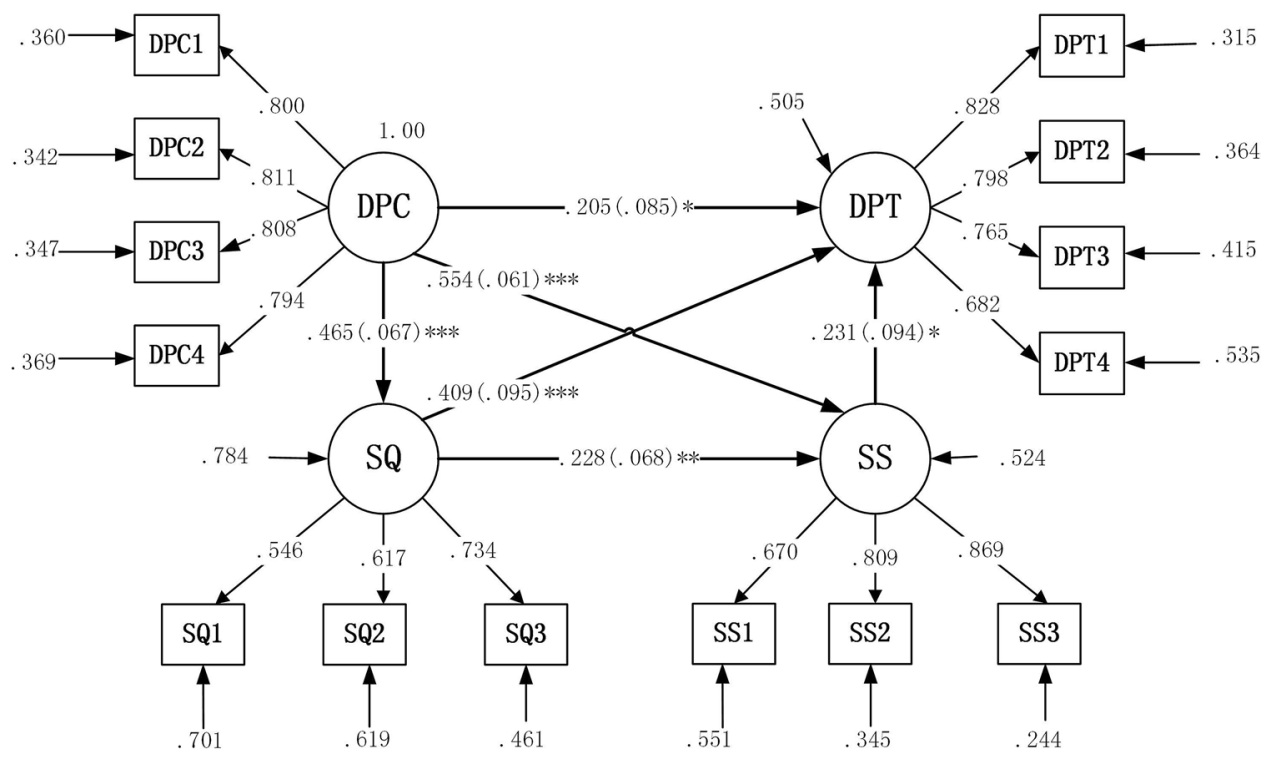

Figure 2. The pathway analysis of the factors influencing doctor-patient trust. The values in the brackets represent the standard error. ${ }^{\star} P<0.05,{ }^{*} P<0.01$, and ${ }^{\star *} P<0.001$. DPC doctor-patient communication, $S Q$ service quality, SS service satisfaction, DPT doctor-patient trust. Fitting of model: Chi-square test of the model fit $=210.535$; degrees of freedom $=71$; RMSA $=0.059 ; \mathrm{CFI}=0.962 ; \mathrm{TLI}=0.952 ; \mathrm{SRMR}=0.039$.

tor-patient trust was 0.342 (95\% CI $(0.191,0.475))$, which accounted for $62.41 \%$ of the total effect. Specifically, doctor-patient communication positively predicted doctor-patient trust via medical service quality $(P=0.004$, $95 \%$ CI $(0.096,0.356)$ ), with an estimated indirect effect of 0.190 ; doctor-patient communication positively predicted doctor-patient trust via service satisfaction $(P=0.039,95 \% \mathrm{CI}(0.034,0.293))$, with an estimated indirect effect of 0.128 ; and doctor-patient communication also significantly predicted doctor-patient trust via the sequential mediation variables of service quality and patient-perceived service satisfaction $(P=0.046,95 \% \mathrm{CI}$ $(0.007,0.058))$, whose estimated multiple indirect effect was only 0.024 . Taken together, the hypotheses in our study were all supported (Table 5).

\section{Discussion}

In the process of medical service delivery, patients are on the weaker side than doctors because patients have little medical knowledge (e.g., prevention and treatment) and possess few ownership or use-rights of medical resources, which leads to the problem of trust when they must entrust their lives and health to doctors. Although doctor-patient trust is not optimistic in China, few studies have examined the effect mechanism of trust and how to establish the patient trust in the doctor. This present study explored the effects of doctor-patient communication, medical service quality, and service satisfaction on patient trust in medical staff using the SEM method.

None of the socio-demographic characteristics, except for the medical institution type, exhibited an association with doctor-patient trust. The highest level of patient trust in medical institutions was observed for the county hospital, but the lowest level was observed for tertiary specialized medical institutions, based on the results. The balance between medical service costs and the effectiveness of disease treatments are importantly related to doctor-patient trust ${ }^{14}$. Patients should show more trust in the county hospital, because the county hospital potentially provides better medical services than TB dispensaries and treatment costs less at the county 


\begin{tabular}{|c|c|c|c|c|c|c|}
\hline \multirow[b]{2}{*}{ Description } & \multirow[b]{2}{*}{ Point estimate } & \multicolumn{3}{|c|}{ Product of coefficients } & \multicolumn{2}{|c|}{$\begin{array}{l}\text { Bootstrap } 1000 \\
\text { times } 95 \% \text { CI } \\
\text { (bias-corrected) }\end{array}$} \\
\hline & & S.E & Est./S.E & $P$-value & Lower & Upper \\
\hline \multicolumn{7}{|l|}{ Effects from SQ to DPT } \\
\hline $\mathrm{SQ} \rightarrow \mathrm{SS} \rightarrow \mathrm{DPT}$ & 0.053 & 0.027 & 1.963 & 0.050 & 0.014 & 0.125 \\
\hline Total effect & 0.462 & 0.091 & 5.06 & $<0.001$ & 0.303 & 0.656 \\
\hline \multicolumn{7}{|l|}{ Effects from DPC to DPT } \\
\hline $\mathrm{DPC} \rightarrow \mathrm{SQ} \rightarrow \mathrm{DPT}$ & 0.190 & 0.065 & 2.91 & 0.004 & 0.096 & 0.356 \\
\hline $\mathrm{DPC} \rightarrow \mathrm{SS} \rightarrow \mathrm{DPT}$ & 0.128 & 0.062 & 2.065 & 0.039 & 0.034 & 0.293 \\
\hline $\mathrm{DPC} \rightarrow \mathrm{SQ} \rightarrow \mathrm{SS} \rightarrow \mathrm{DPT}$ & 0.024 & 0.012 & 1.997 & 0.046 & 0.007 & 0.058 \\
\hline Total indirect effect & 0.342 & 0.071 & 4.806 & $<0.001$ & 0.191 & 0.475 \\
\hline Total effect & 0.548 & 0.041 & 13.349 & $<0.001$ & 0.467 & 0.628 \\
\hline
\end{tabular}

Table 5. Total and indirect effects of doctor-patient communication and service quality on doctor-patient trust. DPC doctor-patient communication, $S Q$ service quality, $S S$ service satisfaction, DPT doctor-patient trust, S.E. standard error, CI confidence interval, bootstrap $=1000$.

hospital than at the tertiary hospital. Hence, the TB dispensaries should strengthen the improvement of medical technology, and the tertiary hospital should consider lower prices for medical services to improve doctor-patient trust. Additionally, the factor analysis showed that the measurements of the constructs displayed good reliability and validity, which provided a possible solution for the measurement of service quality and service satisfaction in future studies. The SEM exhibited good fit indexes, suggesting that our conceptual model was reasonable and had certain guiding value in rebuilding doctor-patient trust in practice.

In the present study, doctor-patient communication showed a significant, direct effect on doctor-patient trust $(P=0.016)$, with the highest total effect. Doctor-patient communication could be considered as the beginning of medical service delivery, which shapes the first impressions of both the doctor and patient. Additionally, effective doctor-patient communication helps to eliminate the psychological barriers and differences between doctors and patients, which all are beneficial to encouraging doctor-patient trust ${ }^{50,51}$. More importantly, medical service quality exerted the greatest direct effect on doctor-patient trust $(b=0.409, P<0.001)$ in our study. Service quality is the core of any service industry and deserves the most attention, particularly in healthcare ${ }^{52,53}$. An improvement in medical service quality, namely, a safe and effective medical service, would increase the trust of patients in doctors and hospitals ${ }^{52}$. Moreover, consistent with the previous study, patient-perceived service satisfaction was another factor that predicted doctor-patient trust, but some studies have implied that patients were not very satisfied with the medical services in China ${ }^{19,54,55}$. Therefore, an urgent need is to improve patient satisfaction with medical services. Doctor-patient communication and medical service quality exerted significant positive effects on service satisfaction, providing solid evidence for methods to improve patient satisfaction in medical practice.

Furthermore, this study clarified the mediating relationship between doctor-patient communication, medical service quality, service satisfaction, and the dependent variable doctor-patient trust. First, sufficient doctor-patient communication positively influenced doctor-patient trust mediated by medical service quality or service satisfaction. According to the traditional trust theory, the interaction or communication between individuals is the starting point for the formation of all social structures, particularly interpersonal trust ${ }^{56,57}$. Communication between the doctor and patient is the prelude to medical delivery behaviour, in which the doctor and patient exchange information about the health check-up, diagnosis, treatment, prognosis, and other important information. Effective communication may improve the patient's experience and perception, namely, patientperceived service quality and satisfaction, of the medical service, which is beneficial to build the trust of patients towards doctors. Additionally, the medical service quality and service satisfaction are considered sequential mediators from doctor-patient communication to doctor-patient trust, a relationship that has not been confirmed in previous studies. After careful consideration, this finding is logical, because effective doctor-patient communication enables medical staff to better understand the patient's health service needs, to provide better services, and thus in turn to improve patient satisfaction with medical services, which is conducive to the establishment of doctor-patient trust ${ }^{4,58}$.

Based on these findings, this study provided some implications for practice. Rebuilding of doctor-patient trust may be achieved by improving doctor-patient communication, medical service quality, and service satisfaction in the process of medical service delivery. First, doctor-patient communication skills must be strengthened, particularly the communication skills of doctors, which are still not very good in China ${ }^{4,59}$. An improvement in doctor-patient communication is conducive to the improvement of medical service quality and patient satisfaction, which are all beneficial to establishing patient trust in medical staff. The main method of doctor-patient communication in China is face-to-face communication, but the previous study reported similar for between screen-to-screen and face-to-face doctor-patient communication ${ }^{60}$; additionally, researchers have documented that a "Photo Stories" presentation contributes to doctor-patient communication ${ }^{61}$, which all provide evidence of future communication methods in China. Importantly, Chinese medical staff must develop their communication skills, such as listening to patients, engaging them in shared decision making about health, and increasing awareness of performance-related feedback in medical practice ${ }^{62-64}$. Certainly, patients should also seriously 
adhere to individual literacy in health training, and with the participation of their families, they should alleviate their discomfort and vulnerability and feel open to express themselves ${ }^{65,66}$.

Moreover, the service quality, which is the foundation of the medical industry, should be improved in reality, which is not only reflected in the professional skills of medical staff but also reflected in their attitudes and basic behaviours in medical service delivery. Hospitals should establish a systematic medical training and learning system to ensure that medical personnel are able to constantly improve their professional talents and cultivate a sense of responsibility, which may decrease the occurrence of lower service quality, adverse events, and medical errors $^{52,67}$. Additionally, the medical staff should be required to establish the "patient-centred" service concept, which embodies the respect and humanistic healthcare in the whole medical service process ${ }^{67}$. Doctors' improper medical practices must also be monitored to provide patients with necessary medical services and products ${ }^{68}$. Crucially, service satisfaction plays a key role in building doctor-patient trust. Medical service satisfaction is always a concern in China, but it does not appear to have been substantially improved, even with the implementation of the medical reforms in $2009^{69}$. Therefore, service satisfaction should be viewed as a feedback index of the quality of medical service in future practice; on the other hand, service satisfaction should also be continuously measured and improved, which may contribute to the establishment of doctor-patient trust.

Nevertheless, several limitations need to be addressed in future studies. First, the sample analysed in this study was limited to participants from Dalian. This sample limits our ability to generalize findings to other regional groups. The problem of trust towards a doctor is not limited to patients with TB, and patients with other diseases also experience the same problem. Further studies should be extended to more diverse patients to test the adaptability of our research model. Second, the data were collected only through self-report measures, which might affect the results of this study. Patients with preferential treatment from the doctor may be more likely to provide positive feedback, which may account for reporting bias. Future studies could combine participants' self-reported measures and content analyses by interviewing them to obtain their opinions and feedback from others. Finally, our findings were based on cross-sectional data, which limit our ability to draw a practical causal conclusion. Although the tested model provides one possible combination of the relationships, receiving more positive feedback might plausibly predict doctor-patient trust. Therefore, longitudinal studies are needed to examine causal or bi-directional relationships between these variables.

\section{Conclusions}

This study empirically explored the effects of doctor-patient communication, medical service quality, and service satisfaction on doctor-patient trust in China, with $564 \mathrm{~TB}$ patients participating in the study. The results of the linear regression analysis identified doctor-patient communication, medical service quality and service satisfaction as direct predictors of doctor-patient trust. Using the SEM method, we found that (1) doctor-patient communication, medical service quality and service satisfaction directly benefited building doctor-patient trust; (2) service quality mediated the relationship between doctor-patient communication and doctor-patient trust; (3) medical service satisfaction mediated the relationship between doctor-patient communication and doctor-patient trust; (4) medical service satisfaction mediated the relationship between medical service quality and doctor-patient trust; and (5) medical service quality and service satisfaction were the sequential mediators from doctor-patient communication to doctor-patient trust. The results have completely supported the research hypotheses we proposed, and doctor-patient communication, medical service quality and service satisfaction positively predicted doctor-patient trust through a direct or indirect path, and this prediction was very good $(R$-square $=0.495)$. These findings not only provide theoretical support for the effect mechanism of patients' trust in medical staff but also a valid guide for rebuilding doctor-patient trust in practice.

Received: 23 March 2020; Accepted: 24 November 2020

Published online: 15 December 2020

\section{References}

1. Eveleigh, R. M. et al. An overview of 19 instruments assessing the doctor-patient relationship: Different models or concepts are used. J. Clin. Epidemiol. 65, 10-15. https://doi.org/10.1016/j.jclinepi.2011.05.011 (2012).

2. Sherman, K. J. et al. Doctor-patient trust among chronic pain patients on chronic opioid therapy after opioid risk reduction initiatives: A survey. J. Am. Board Fam. Med. JABFM 31, 578-587. https://doi.org/10.3122/jabfm.2018.04.180021 (2018).

3. Camerini, A. L. \& Schulz, P. J. Patients' need for information provision and perceived participation in decision making in doctor-patient consultation: Micro-cultural differences between French- and Italian-speaking Switzerland. Patient Educ. Couns. 99, 462-469. https://doi.org/10.1016/j.pec.2015.10.018 (2016).

4. Pun, J. K. H., Chan, E. A., Wang, S. \& Slade, D. Health professional-patient communication practices in East Asia: An integrative review of an emerging field of research and practice in Hong Kong, South Korea, Japan, Taiwan, and Mainland China. Patient Educ. Couns. 101, 1193-1206. https://doi.org/10.1016/j.pec.2018.01.018 (2018).

5. Peng, W., Ding, G., Tang, Q. \& Xu, L. Z. Continuing violence against medical personnel in China: A flagrant violation of Chinese law. BioSci. Trends 10, 240-243. https://doi.org/10.5582/bst.2016.01094 (2016).

6. Zhao, D. \& Zhang, Z. Changes in public trust in physicians: empirical evidence from China. Front. Med. 13, 504-510. https://doi. org/10.1007/s11684-018-0666-4 (2019).

7. Hesketh, T., Wu, D., Mao, L. \& Ma, N. Violence against doctors in China. BMJ Br. Med. J. https://doi.org/10.1136/bmj.e5730 (2012).

8. Xu, W. Violence against doctors in China. Lancet (London, England) 384, 745-745. https://doi.org/10.1016/s0140-6736(14)61438 -0 (2014).

9. Zhao, L., Zhang, X.-Y., Bai, G.-Y. \& Wang, Y.-G. Violence against doctors in China. Lancet (London, England) 384, 744-744. https ://doi.org/10.1016/s0140-6736(14)61436-7 (2014).

10. Jie, L. New generations of Chinese doctors face crisis. Lancet (London, England) 379, 2012. https://doi.org/10.1016/s0140 $-6736(12) 60774-0$ (1878)

11. The Lancet. Violence against doctors: Why China? Why now? What next?. Lancet (London, England) 383, 1013. https://doi. org/10.1016/s0140-6736(14)60501-8 (2014). 
12. Qanitha, A. et al. Adherence to guideline recommendations for coronary angiography in a poor South-East Asian setting: Impact on short- and medium-term clinical outcomes. Sci. Rep. 9, 19163. https://doi.org/10.1038/s41598-019-55299-0 (2019).

13. Zhou, P. L. \& Grady, S. C. Three modes of power operation: Understanding doctor-patient conflicts in Chinas hospital therapeutic landscapes. Health Place 42, 137-147. https://doi.org/10.1016/j.healthplace.2016.09.005 (2016).

14. Shan, L. et al. Patient satisfaction with hospital inpatient care: Effects of trust, medical insurance and perceived quality of care. PLoS ONE 11, e0164366. https://doi.org/10.1371/journal.pone.0164366 (2016).

15. Yang, T. \& Wu, Y. A study on the influence of patient participation on patient trust-based on sample survey in China. Front. Psychol. 9, 2189. https://doi.org/10.3389/fpsyg.2018.02189 (2018).

16. Dong, E. et al. Construction and validation of a preliminary Chinese version of the Wake Forest Physician Trust Scale. Med. Sci. Monitor Int. Med. J. Exp. Clin. Res. 20, 1142-1150. https://doi.org/10.12659/msm.889992 (2014).

17. Lu, X., Zhang, R., Wu, W., Shang, X. \& Liu, M. Relationship between internet health information and patient compliance based on trust: Empirical study. J. Med. Internet Res. 20, e253. https://doi.org/10.2196/jmir.9364 (2018).

18. Lee, Y. Y. \& Lin, J. L. The effects of trust in physician on self-efficacy, adherence and diabetes outcomes. Soc. Sci. Med. 1982(68), 1060-1068. https://doi.org/10.1016/j.socscimed.2008.12.033 (2009).

19. Zhao, D. H., Rao, K. Q. \& Zhang, Z. R. Patient trust in physicians: Empirical evidence from Shanghai, China. Chin. Med. J. 129, 814-818. https://doi.org/10.4103/0366-6999.178971 (2016).

20. Nie, J. B. et al. The vicious circle of patient-physician mistrust in China: Health professionals' perspectives, institutional conflict of interest, and building trust through medical professionalism. Dev. World Bioethics 18, 26-36. https://doi.org/10.1111/dewb.12170 (2018).

21. Zhang, R., Lu, X., Wu, W., Shang, X. \& Liu, M. Mature or emerging? The impact of treatment-related internet health information seeking on patients' trust in physicians. Int. J. Environ. Res. Public Health. https://doi.org/10.3390/ijerph15091855 (2018).

22. Petrocchi, S. et al. Interpersonal trust in doctor-patient relation: Evidence from dyadic analysis and association with quality of dyadic communication. Soc. Sci. Med. 235, 8. https://doi.org/10.1016/j.socscimed.2019.112391 (2019).

23. Thom, D. H., Hall, M. A. \& Pawlson, L. G. Measuring patients' trust in physicians when assessing quality of care. Health Aff. 23, 124-132. https://doi.org/10.1377/hlthaff.23.4.124 (2004).

24. Tang, L. Y. The influences of patient's trust in medical service and attitude towards health policy on patient's overall satisfaction with medical service and sub satisfaction in China. BMC Public Health 11, 8. https://doi.org/10.1186/1471-2458-11-472 (2011).

25. Hsieh, V. C., Hsieh, M. L., Chiang, J. H., Chien, A. \& Hsieh, M. S. Emergency department visits and disease burden attributable to ambulatory care sensitive conditions in elderly adults. Sci. Rep. 9, 3811. https://doi.org/10.1038/s41598-019-40206-4 (2019).

26. Donabedian, A. The quality of care. How can it be assessed?. JAMA 260, 1743-1748. https://doi.org/10.1001/jama.260.12.1743 (1988).

27. Haugland, H., Rehn, M., Klepstad, P., Kruger, A. \& Grp, E.Q.-C. Developing quality indicators for physician-staffed emergency medical services: A consensus process. Scand. J. Trauma Resusc. Emerg. Med. 25, 8. https://doi.org/10.1186/s13049-017-0362-4 (2017).

28. Gardner, K. \& Chapple, A. Barriers to referral in patients with angina: Qualitative study. Br. Med. J. 319, 418-421. https://doi. org/10.1136/bmj.319.7207.418 (1999).

29. Dube, C. E., O’Donnell, J. F. \& Novack, D. H. Communication skills for preventive interventions. Acad. Med. 75, S45-S54. https ://doi.org/10.1097/00001888-200007001-00007 (2000).

30. Liu, C. \& Zheng, Y. The predictors of consumer behavior in relation to organic food in the context of food safety incidents: Advancing hyper attention theory within an stimulus-organism-response model. Front. Psychol. 10, 2512. https://doi.org/10.3389/fpsyg .2019.02512 (2019).

31. Chang, Y. W., Hsu, P. Y., Wang, Y. \& Chang, P. Y. Integration of online and offline health services: The role of doctor-patient online interaction. Patient Educ. Couns. 102, 1905-1910. https://doi.org/10.1016/j.pec.2019.04.018 (2019).

32. Peng, Y. X., Yin, P. P., Deng, Z. H. \& Wang, R. X. Patient-Physician Interaction and Trust in Online Health Community: The role of perceived usefulness of health information and services. Int. J. Environ. Res. Public Health 17, 13. https://doi.org/10.3390/ijerp h17010139 (2020).

33. Sutton, S. Social-psychological approaches to understanding addictive behaviours: Attitude-behaviour and decision-making models. Br. J. Addict. 82, 355-370. https://doi.org/10.1111/j.1360-0443.1987.tb01492.x (1987).

34. Prizer, L. P. et al. Using social exchange theory to understand non-terminal palliative care referral practices for Parkinson's disease patients. Palliat. Med. 31, 861-867. https://doi.org/10.1177/0269216317701383 (2017).

35. Liu, K. et al. Identification and prediction of tuberculosis in Eastern China: Analyses from 10-year POPULATION-BASED NOTIFICATION DATA in Zhejiang Province, China. Sci. Rep. 10, 7425. https://doi.org/10.1038/s41598-020-64387-5 (2020).

36. Zhu, S., Xia, L., Yu, S., Chen, S. \& Zhang, J. The burden and challenges of tuberculosis in China: Findings from the Global Burden of Disease Study 2015. Sci. Rep. 7, 14601. https://doi.org/10.1038/s41598-017-15024-1 (2017).

37. Liu, Y. et al. Out-of-pocket payments and economic consequences from tuberculosis care in eastern China: Income inequality. Infect. Diseases Poverty 9, 14. https://doi.org/10.1186/s40249-020-0623-8 (2020).

38. Offit, K., Groeger, E., Turner, S., Wadsworth, E. A. \& Weiser, M. A. The, "duty to warn" a patient's family members about hereditary disease risks. JAMA 292, 1469-1473. https://doi.org/10.1001/jama.292.12.1469 (2004).

39. Baker, E. F. et al. Law Enforcement and emergency medicine: An ethical analysis. Ann. Emerg. Med. 68, 599-607. https://doi. org/10.1016/j.annemergmed.2016.02.013 (2016).

40. Juarez-Reyes, M., Gallivan, M., Chyorny, A., O'Keeffe, L. \& Shah, N. S. Completion rate and side-effect profile of three-month isoniazid and rifapentine treatment for latent tuberculosis infection in an Urban County Jail. Open Forum Infect. Diseases 3, ofv220. https://doi.org/10.1093/ofid/ofv220 (2016).

41. Du, L. et al. Determinants of medication adherence for pulmonary tuberculosis patients during continuation phase in Dalian, Northeast China. Patient Preference Adherence 14, 1119-1128. https://doi.org/10.2147/ppa.S243734 (2020).

42. Hays, R. D., Chawla, N., Kent, E. E. \& Arora, N. K. Measurement equivalence of the Consumer Assessment of Healthcare Providers and Systems (CAHPS((R))) Medicare survey items between Whites and Asians. Qual. Life Res. Int. J. Qual. Life Aspects Treat. Care Rehabilit. 26, 311-318. https://doi.org/10.1007/s11136-016-1383-6 (2017).

43. Morales, L. S., Elliott, M. N., Weech-Maldonado, R., Spritzer, K. L. \& Hays, R. D. Differences in CAHPS adult survey reports and ratings by race and ethnicity: An analysis of the National CAHPS benchmarking data 1.0. Health Services Res. 36, 595-617 (2001).

44. Hall, M. A. et al. Measuring patients' trust in their primary care providers. Med. Care Res. Rev. MCRR 59, 293-318. https://doi. org/10.1177/1077558702059003004 (2002).

45. Hall, M. A., Dugan, E., Zheng, B. \& Mishra, A. K. Trust in physicians and medical institutions: What is it, can it be measured, and does it matter?. Milbank Quart. 79, 613-639. https://doi.org/10.1111/1468-0009.00223 (2001).

46. Hayes, A. F. Introduction to Mediation, Moderation, and Conditional Process Analysis: A Regression-Based Approach (Guilford Press, New York, 2018).

47. MacKinnon, D. Introduction to Statistical Mediation Analysis (Multivariate Applications Series) (Erlbaum Psych Press, Routledge, 2008).

48. Jackson, D. L., Gillaspy, J. A. \& Purc-Stephenson, R. Reporting practices in confirmatory factor analysis: An overview and some recommendations. Psychol. Methods 14, 6-23. https://doi.org/10.1037/a0014694 (2009). 
49. Hayes, A. F. Beyond Baron and Kenny: Statistical mediation analysis in the new millennium. Commun. Monogr. 76, 408-420. https ://doi.org/10.1080/03637750903310360 (2009).

50. Jolles, E. P., Clark, A. M. \& Braam, B. Getting the message across: Opportunities and obstacles in effective communication in hypertension care. J. Hypertens. 30, 1500-1510. https://doi.org/10.1097/HJH.0b013e32835476e1 (2012).

51. Cantwell, B. M. \& Ramirez, A. J. Doctor-patient communication: A study of junior house officers. Med. Educ. 31, 17-21. https:// doi.org/10.1111/j.1365-2923.1997.tb00037.x (1997).

52. Taylor, B. B. et al. Do medical inpatients who report poor service quality experience more adverse events and medical errors?. Med Care 46, 224-228. https://doi.org/10.1097/MLR.0b013e3181589ba4 (2008).

53. Chang, C. S., Chen, S. Y. \& Lan, Y. T. Service quality, trust, and patient satisfaction in interpersonal-based medical service encounters. BMC Health Services Res. 13, 11. https://doi.org/10.1186/1472-6963-13-22 (2013).

54. Wang, W. et al. Factors influencing trust towards physicians among patients from 12 hospitals in China. Am. J. Health Behav. 42, 19-30. https://doi.org/10.5993/ajhb.42.6.3 (2018).

55. Yan, Y. The ethics and politics of patient-physician mistrust in contemporary China. Developing World Bioethics 18, 7-15. https ://doi.org/10.1111/dewb.12155 (2018).

56. Gong, Z. W., Wang, H., Guo, W. W., Gong, Z. J. \& Wei, G. Measuring trust in social networks based on linear uncertainty theory. Inf. Sci. 508, 154-172. https://doi.org/10.1016/j.ins.2019.08.055 (2020).

57. Pearson, S. D. \& Raeke, L. H. Patients' trust in physicians: Many theories, few measures, and little data. J. Gen. Intern. Med. 15, 509-513. https://doi.org/10.1046/j.1525-1497.2000.11002.x (2000).

58. Shaw, A., Ibrahim, S., Reid, F., Ussher, M. \& Rowlands, G. Patients' perspectives of the doctor-patient relationship and information giving across a range of literacy levels. Patient Educ. Couns. 75, 114-120. https://doi.org/10.1016/j.pec.2008.09.026 (2009).

59. Liu, X. C. et al. Doctor-patient communication skills training in mainland China: A systematic review of the literature. Patient Educ. Couns. 98, 3-14. https://doi.org/10.1016/j.pec.2014.09.012 (2015).

60. Tates, K., Antheunis, M. L., Kanters, S., Nieboer, T. E. \& Gerritse, M. B. The effect of screen-to-screen versus face-to-face consultation on doctor-patient communication: An experimental study with simulated patients. J. Med. Internet Res. 19, e421. https://doi. org/10.2196/jmir.8033 (2017).

61. van't Jagt, R. K. et al. Using photo stories to support doctor-patient communication: Evaluating a communicative health literacy intervention for older adults. Int. J. Environ. Res. Public Health. https://doi.org/10.3390/ijerph16193726 (2019).

62. Gulbrandsen, P. Shared decision making: Improving doctor-patient communication. BMJ (Clinical Research ed.) 368, m97. https ://doi.org/10.1136/bmj.m97 (2020).

63. Sehlbach, C. et al. Learning in the workplace: Use of informal feedback cues in doctor-patient communication. Med. Educ. https ://doi.org/10.1111/medu.14148 (2020).

64. Yun, J. Y. et al. Changing characteristics of the empathic communication network after empathy-enhancement program for medical students. Sci. Rep. 8, 15092. https://doi.org/10.1038/s41598-018-33501-z (2018).

65. Bientzle, M. et al. Impact of scientific versus emotional wording of patient questions on doctor-patient communication in an internet forum: A randomized controlled experiment with medical students. J. Med. Internet Res. 17, e268. https://doi.org/10.2196/ jmir.4597 (2015)

66. Fillon, M. New tool improves doctor-patient communication. J. Natl. Cancer Inst. https://doi.org/10.1093/jnci/djv116 (2015)

67. Liu, A. J. et al. A GRA-based method for evaluating medical service quality. IEEE Access 7, 34252-34264. https://doi.org/10.1109/ access.2019.2903684 (2019).

68. Kerr, E. A. \& Hofer, T. P. Deintensification of routine medical services: The next frontier for improving care quality. JAMA Internal Med. 176, 978-980. https://doi.org/10.1001/jamainternmed.2016.2292 (2016).

69. Ta, Y. Q., Zhu, Y. S. \& Fu, H. Q. Trends in access to health services, financial protection and satisfaction between 2010 and 2016 : Has China achieved the goals of its health system reform?. Soc. Sci. Med. 245, 12. https://doi.org/10.1016/j.socscimed.2019.11271 $5(2020)$

\section{Acknowledgements}

We thank all 15 interviewers, who came from the School of Public Health at Dalian Medical University, for their efforts in collecting the data. In addition, we are grateful to all the medical personnel from the four investigative districts who contributed to our study. Finally, we express gratitude to the TB patients who made our study possible.

\section{Author contributions}

L.Z. and L.D. contributed to conception and design, and management of the whole study. L.D. contributed to analysis and interpretation of data, and draft the article. L.Z., X.Z. and Y.Z. contributed to critical revision of the manuscript for important intellectual content. X.C., X.Z., Y.Z., R.W., J.X. and H.J. was responsible for data collection. All authors read and approved the final manuscript.

\section{Funding}

None.

\section{Competing interests}

The authors declare no competing interests.

\section{Additional information}

Correspondence and requests for materials should be addressed to L.Z.

Reprints and permissions information is available at www.nature.com/reprints.

Publisher's note Springer Nature remains neutral with regard to jurisdictional claims in published maps and institutional affiliations. 
(c) (i) Open Access This article is licensed under a Creative Commons Attribution 4.0 International cc) License, which permits use, sharing, adaptation, distribution and reproduction in any medium or format, as long as you give appropriate credit to the original author(s) and the source, provide a link to the Creative Commons licence, and indicate if changes were made. The images or other third party material in this article are included in the article's Creative Commons licence, unless indicated otherwise in a credit line to the material. If material is not included in the article's Creative Commons licence and your intended use is not permitted by statutory regulation or exceeds the permitted use, you will need to obtain permission directly from the copyright holder. To view a copy of this licence, visit http://creativecommons.org/licenses/by/4.0/.

(C) The Author(s) 2020 